\title{
Age, condition and dominance-related sexual ornament size before and during the breeding season in the black grouse Lyrurus tetrix
}

\author{
Harris Sarah ${ }^{1,{ }^{*}}$, Kervinen Matti ${ }^{2}$, Lebigre Christophe ${ }^{3}$, W.Pike Thomas ${ }^{1}$, Soulsbury Carl D. ${ }^{1}$
}

${ }^{1}$ School of Life Sciences; University of Lincoln, Joseph Banks Laboratories, Green Lane; Lincoln LN6

7DL, UK

${ }^{2}$ Department of Biological and Environmental Science; University of Jyväskylä; P.O. Box 35, 40014

Jyväskylä, Finland

3 IFREMER, Unité Sciences et Technologies Halieutiques; Centre Bretagne, ZI de la Pointe du Diable,

CS 10070; F- 29280 Plouzané, France

*Corresponding author : Sarah Harris, email address : sarah.e.harris@btinternet.com

\begin{abstract}
:
Male ornaments function as honest cues of male quality in many species and are subject to intra- and intersexual selection. These ornaments are generally studied during peak expression, however their size outside the breeding season may determine ultimate ornament size and costliness, and as such reproductive success. We investigated whether male black grouse Lyrurus tetrix eye comb size was related to age, condition and measures of male dominance before and during the breeding season. Total combined eye comb size began to increase $\sim 70$ days before the start of the breeding season. Adult males (aged $\geq 2$ years old) had consistently larger eye combs than younger males ( 1 year old) both before and during the breeding season. Heavier and more dominant adult males (attending the lek more frequently and successfully reproducing) had larger eye combs. For younger males, those that were heavier had larger eye combs. Additionally, males that spent more time on the lek showed increased eye comb size as the breeding season approached. Overall we find that ornament size is positively related to dominance and condition before and during the breeding season. Since dominance is accrued through year-round interactions in many species, the ability to maintain larger signals over prolonged periods, including outside of the breeding season, is likely to be beneficial for adults. For younger males, it is likely that they cannot sustain or are constrained from producing larger eye combs over long periods of time. They therefore prioritise growth of their ornaments later, and according to the amount of time they spend on the lek.
\end{abstract}




\section{Introduction}

Males of many species display elaborate ornaments that function as honest indicators of individual quality if ornament production or maintenance comes at a cost to the bearer (Zahavi 1975, Andersson 1994). These ornaments may function as intersexual signals, whereby females can assess and choose potential mates (Hill 1991), intrasexual signals, whereby males can assess dominance in conspecific males (Chaine and Lyon 2008), or both (Griggio et al. 2007). The expression of sexually-selected traits during an individual's lifespan is extremely dynamic, increasing or decreasing with age (e.g. Kervinen et al. 2015) and going through cycles of renewal as, for example, deer annually shed and regrow antlers, and birds moult and replace brightly coloured plumage (e.g. Kierdorf, Li and Price 2009, Saino et al. 2013). Thus, many ornaments are not displayed continuously, but grown expressly for the breeding season, and then moulted or contracted when no longer required (Jenni and Winkler 2011). For example, a bird's plumage-based displays reflect quality during moult thus reflecting previous condition (e.g. McGraw et al. 2002, Serra et al. 2007, Harms et al. 2015). In contrast, some traits, including behaviours, may dynamically reflect current condition (e.g. vocalisations: Vannoni and McElligott 2009). Skin-based (integumentary) ornaments are one such example of this, and are widespread throughout the animal kingdom (fish: Pike et al. 2010; birds: Prum and Torres 2003, Rosenthal et al. 2012; reptiles: Langkilde and Boronow 2010). These structures have been shown to vary in colour and size and can fluctuate to reflect changes in condition rapidly; for example skin colouration in the blue-footed booby (Sula nebouxii) can change according to nutritional condition in as little as 48 hours (Velando, Beamonte-Barrientos and Torres 2006; also see Doucet and Mennill 2009, Butler and McGraw 2011). This suggests integumentary traits may act as cues of current phenotypic quality (Perez-Rodriguez 2008, Hill, Hood and Huggins 2009).

Integumentary ornament size is typically mediated by androgens, which can act as immunosuppressants or oxidative stressors, making the signal physiologically or energetically costly to express (Folstad and Karter 1992, von Schantz et al. 1999, AlonsoAlvarez et al. 2007, Mougeot et al. 2009 and references therein). This suggests that only high quality males are able to mediate these costs, especially in combination with other factors influencing their current condition; for example food availability or parasite burden. The ability to cope with these costs and, as such, the resources available for investment into sexual interactions may vary further with age (Yoccoz et al. 2002, Nieminen et al. 2016). For example, in younger males, investment may be allocated instead to growth or development 
(Nussey et al. 2009, Kervinen et al. 2015). Due to the costs involved with expressing such traits, these ornaments are usually only largest when dominance is more important, i.e. during the breeding season (e.g. the bill knob of mute swans Cygnus olor: Horrocks, Perrins and Charmantier 2009). However, many species interact outside of the breeding season, often particularly intensively in the months or weeks leading up to the period of maximum trait expression; these interactions can lead to differences in dominance status and reproductive success (e.g. Marra and Holmes 2001, Yoshino and Goshima 2002, Pryke et al. 2002, Mougeot et al. 2005 a, c, Poisbleau et al. 2006, Reudink et al. 2009). Despite this, most investigations focus on peak expression or discrete periods before and during breeding (e.g. Forstmeier 2002, Faivre et al. 2003, Jawor et al. 2004, Miller and Brooks 2005, Mougeot, Redpath and Piertney 2006, Dobson et al. 2008, Murphy et al. 2009).

Research shows that developing larger static (e.g. bone-based such as antlers) traits is costly (Walther and Clayton 2005). It therefore follows that developing such traits earlier in the lead-up to, or during, the breeding season is likely to come at a higher physiological and energetic cost (e.g. Møller 1994, Lantz and Karubian 2001, Peters, Astheimer, Cockburn 2001). The claim that costly ornaments honestly signal quality thus needs to be understood in a dynamic context, particularly for more transient signals (i.e. integumentary or skin-based), as this may only be true in some phases of growth; modelling suggests that higher quality individuals should delay growth until closer to breeding (Rands, Evans and Johnstone 2011). For example, the red grouse Lagopus lagopus scotica has two seasonal ornament growth peaks; autumn and spring. Those with the largest combs during autumn become more dominant and are able to establish a territory, whilst those failing to do this do not survive to see the breeding season (Mougeot et al. 2005a, Mougeot et al. 2003a, c). We also know that developing the largest or most elaborate ornament may be facilitated by periods of earlier and more accelerated growth (e.g. Barnard 1995, Bartoš and Losos 1997, Dunn and Cockburn 1999, Ninni et al. 2004, Siefferman, Hill and Dobson 2005, Lee, Monaghan and Metcalfe 2012). Expression of these signals and the information conveyed by their interactions can change dramatically before the breeding season, for example due to shifts in social status (Kitaysky, Wingfield and Piatt 1999, Setchell and Dixson 2001, Oliveira 2004), and conspecifics may dynamically assess this (Torres and Velando 2003) and implement flexible patterns of reproductive effort (Nieminen et al. 2016). The period prior to the breeding season itself may even determine the ultimate size of the ornament, as well as its costliness, i.e. its condition-dependence (Bartoš and Losos 1997, Rands, Evans and Johnstone 2011). Thus, 
taking a snapshot of ornaments, that may be partially developed, prior to breeding may be misleading (Rands, Evans and Johnstone 2011).

The black grouse Lyrurus tetrix is a lekking Galliform species with strong intersexual and intrasexual selection, in which copulations are skewed towards a few superior males (Alatalo, Höglund and Sutherland 1992, Kokko and Lindström 1996, Kervinen et al. 2016). Males have a number of morphological and behavioural traits that are used for both intersexual and intrasexual signalling (Hovi et al. 1994, Höglund, Johansson and Pelabon 1997, Rintamäki et al. 1997, 2000, 2001, Siitari et al. 2007, Hämäläinen et al. 2012, Lebigre, Alatalo and Siitari 2013). Of these, their testosterone-dependent red eye combs are the most variable in size (Rintamäki et al. 2000, Kervinen et al. 2015), peaking during the breeding season (Fig 1). However, male dominance is acquired and maintained through multi-annual, year-round interactions (Kokko et al. 1998, Rintamäki et al. 1999, Siitari et al. 2007), similar to the patterns shown in red grouse (Mougeot et al. 2005a, Mougeot et al. 2003a, b), suggesting that the top males should have larger eye combs at all times. The breeding season occurs over approximately 2 weeks during spring, but winter flocking and dominance-related interactions begin up to 3-5 months before this (Alatalo, Höglund and Lundberg 1991, Lebigre et al. 2012). During this period, physiological stress levels increase in red grouse, and likely enforce the honesty of signals (Bortolotti et al. 2009). Those in better condition or phenotypic quality are likely to cope more successfully with prolonged periods of expressing larger eye combs. As resources available for investment and, accordingly, dominance vary across an individual's lifetime, we also investigated the relationship between age and ornament expression. Using a longitudinal dataset of individual eye comb size across multiple years, we tested whether condition or dominance were related to eye comb sizes before and during the breeding season, and how this varied with age.

\section{Material and Methods}

\section{Data collection}

Black grouse were studied at 5 protected lek sites in central Finland (centred around Petäjävesi: lat. $62^{\circ} 25^{\prime} \mathrm{N}$, long. $25^{\circ} 18^{\prime} \mathrm{E}$ ) from January-May, 2001-13 and 2015. Individuals were caught (during January-May) with oat-baited walk-in traps, using standard protocols (see Siitari et al. 2007, Lebigre et al. 2012). Each individual was banded, weighed (to nearest $10 \mathrm{~g}$ ) and aged as adult ( $\geq 2$ years old) or younger ( 1 year old), based on plumage differences (Helminen 1963). Eye combs were recorded on a digital video camera with a $1 \mathrm{~cm}$ scale 
reference. The area of each eye comb $\left(\mathrm{cm}^{2}\right)$ was calculated using ImageJ software (Rasband 2012), and then summed to get total eye comb area for each individual $\left(\mathrm{cm}^{2}\right)$. Repeatability for these measurements was calculated using ICC function (Wolak et al. 2012) in R (ICC $=0.986,95 \% \mathrm{CI}=0.97 / 0.99, \mathrm{n}=50)$, with a margin of error in estimated comb size of only $1 \%$.

\section{Behavioural data}

During the mating season (ca. 2 weeks in late April - early May) behaviours of ringed males were recorded daily, at regular intervals from 03:00 to 08:00 am as this is primary period of activity and when copulations occur. Behaviours (fighting, hissing, rookooing, inactive; Höglund et al. 1997) and the spatial location of each male were scan sampled at regular intervals (documented as 'activity maps'). Total number of copulations, lek attendance (proportional to the highest attending male on the same lek that year), and the centre of each male's territory (median coordinates of observations) were calculated for all males. Distance from lek centre was calculated as the linear distance of each male's territory centre from the lek centre (median coordinates of all observations of all males). There is strong sexual selection on male behavioural traits of which lek attendance, distance from lek centre and number of copulations achieved accurately capture male dominance (Kervinen et al. 2016).

\section{Statistical Analysis}

We tested the idea that males of differing age, condition and dominance status would vary in the timing of eye comb size change. This was analysed using linear mixed-effect models (LMMs). In each model, the linear and quadratic terms of Julian date were included to account for possible non-linearity of ornament growth. A polynomial linear regression was used as it is appropriate for investigating the increasing exponential growth leading to the breeding season. Black grouse males forage in the forests surrounding the lek sites after the breeding season, meaning they cannot be captured so we lack data on the decline of eye comb size.

We tested for correlations between eye comb size and the following four dominanceand condition-related measures for both age groups: (a) distance from lek centre, as dominant males hold territories closer to the lek centre (Rintamäki et al. 1997); (b) lek attendance, as dominant males attend the lek most often (Alatalo et al. 1996); (c) copulations, as only the dominant males reproduce (Alatalo et al. 1991); (d) body mass (g), a measure of condition (e.g. Alatalo et al. 1996) as heavier males have more resources (condition-dependence) to 
invest both in ornament growth and dominance-related activities (Willebrand and Marcström 1989, Rintamäki et al. 2001, Nieminen et al. 2016). Lek attendance was included as a binary factor, based on high $(\geq 80 \%)$ and low $(<80 \%)$ attendance, because of a sharp increase in mating success for those with $\geq 80 \%$ attendance (Kervinen, Lebigre and Soulsbury 2016). All models had a Gaussian error structure and used total eye comb size (combined area of left and right eye comb) as the dependent variable. In all models, individual identity, year and site were included as random effects to control for repeated measures, cohort and differences between sites, such as resources.

In order to test for differences in eye comb size across the time period before and during the breeding season, each variable was first tested in interaction with Julian date (linear and quadratic). The interaction terms were subsequently removed in a backward stepwise manner if non-significant. We first quantified the differences in eye combs size between adults ( $\geq 2$ years old) and younger males ( $<1$ year old), identified because the majority of morphological and behavioural trait development occurs between 1 and 2 years old in black grouse, with mating being largely unsuccessful until 2 years old (Alatalo et al. 1992, Kervinen et al. 2012). Any significant interactions between age and Julian date would indicate a difference in the eye comb growth patterns between groups. We then tested relationships with dominance- and condition-measures. For these analyses adults and younger males were analysed separately, as only a minority of younger males participate in dominance-related behaviours, and strong age-dependency in morphological and behavioural traits may over or under emphasise patterns (Kervinen et al. 2012, 2015).

Lastly, we tested whether changes in dominance between years led to differences in growth of eye combs. To this end, we subtracted the value of individuals' dominance measures (lek attendance, distance from lek centre) from the previous year's values, respectively. A negative value for distance from lek centre would therefore indicate that a male was moving closer to the lek centre and becoming more dominant. Conversely, a positive value for lek attendance indicated more time spent at the lek and greater dominance. We carried out a LMM with total eye comb size, Julian date (linear and quadratic) and the between-year differences as fixed factors. Similarly to the condition and dominance analyses; identity, age and year were included as random effects and backward stepwise removal of interactions was carried out. We used only adult males for this analyses to avoid the change in traits between younger and adults confounding results (Kervinen et al. 2015). Models were run using the lme4 function (Bates, Maechler and Bolker 2015) along with the lmerTest 
function (Kuznetsova, Brockhoff and Christensen 2015). All models were run in R version 3.1.2 (R Development Core Team 2012).

\section{Results}

\section{Age differences in eye comb growth}

In total, we measured 577 adult males a total of 830 times, with individual adults measured between 1 and 8 times across their lifetimes. Within each year, most males were sampled once (704 times), but some were measured multiple times within a year (two measures $=98$ measured twice, 18 measured three times, 10 measured four times). We measured 800 younger males, with most being measured once (753) and few being measured twice or more (41 measured twice, 6 measured three times).

Total eye comb size was significantly related to the linear and quadratic terms of Julian date (linear: Estimate $\pm \mathrm{SE}=-0.04 \pm 0.002, \mathrm{t}=-14.30, \mathrm{P}<0.001$; quadratic: Estimate \pm $\left.\mathrm{SE}=6.57 \times 10^{-4} \pm 2.46 \times 10^{-5}, \mathrm{t}=26.67, \mathrm{P}<0.001\right)$. Adult males had larger eye combs than younger males (Estimate $\pm \mathrm{SE}=1.80 \pm 0.06, \mathrm{t}=30.49, \mathrm{P}<0.001$ ), and there was a significant interaction between age and quadratic Julian date (Estimate $\pm \mathrm{SE}=3.78 \times 10^{-5} \pm 1.33 \times 10^{-5}$, $\mathrm{t}=2.84, \mathrm{P}=0.005$ ), but not linear Julian date. Adult males always had larger eye combs and the increase in size of eye combs was faster than in younger males (Fig 1c).

\section{Adult males and dominance-related eye comb growth-scheduling}

For adult males, heavier males always had larger eye combs (Table 1; Fig 2a). Similarly, males that attended the lek more frequently (Fig 2b) had higher mating success (Fig 2c) and larger eye combs. There was a non-significant trend for black grouse with territories closer to the lek centre to have larger eye combs.

\section{Younger males and dominance-related eye comb growth-scheduling}

Younger males that were heavier had consistently larger eye combs (Table 1; Fig 3a). In addition, those males that; attended the lek frequently (Fig 3b), had territories closer to the lek centre (Fig 3c) and those that had higher mating success (Fig 3d) grew larger eye combs close to the breeding season (Table 1). However, these more dominant males did not grow larger eye combs early on, prior to the breeding season. 


\section{Changing status and eye comb growth}

Adult males that increased their lek attendance between years significantly increased eye comb size, especially closer to the breeding season (Table 2; Fig 4), but there was no effect of moving closer to the lek centre (Table 2).

\section{Discussion}

\section{Age differences in eye comb growth}

Younger males are typically lighter than adult males and presumably have fewer resources available for allocation to ornament expression (Kervinen et al. 2015). Accordingly, younger black grouse males have been shown to rank lower on the lek, achieving little reproductive success, with only a minority participating in dominance-related activities such as fighting and lek attendance (Brittas and Willebrand 1991, Alatalo et al. 1992, Kokko and Lindström 1996, Kervinen et al. 2012). In line with these results, we found that younger males had consistently smaller eye combs than adult males. This result is similar to those reported in in other taxa, for example in male red deer (Cervus elaphus) investment into rutting and antler growth (both required for dominance) is lower in young males than healthy adult males (Nussey et al. 2009; see Balbontín et al. 2007, Evans, Gustafsson and Sheldon 2011 for additional examples). Low younger investment is also unsurprising as younger males that significantly invest in early, prolonged ornament growth may incur costs of reduced future success in ornament expression, reproduction and survival (Stearns 1989, Hunt et al. 2004, Siitari et al. 2007, Kervinen et al. 2015, see Metcalfe and Monaghan 2001 for a review). Hence, delayed ornament expression until full maturity may be beneficial to male lifetime reproductive success (Kokko 1997, Kervinen et al. 2015).

\section{Adult males and dominance-related eye comb size}

Heavier adult males had larger eye combs before and during the breeding season. Previous studies have demonstrated that ornament expression is condition-dependent (Holzer, Jacot and Brinkhof 2003, Cotton, Fowler and Pomiankowski 2004, Poisbleau et al. 2006, Emlen et al. 2012, but see Badyaev and Duckworth 2003). High testosterone levels allow males to express larger eye combs and be more reproductively successful but also result in trade-offs between ornament expression and immune function or oxidative defence (Alatalo et al. 1996, Rintamäki et al. 2000, Mougeot et al. 2009, Martínez-Padilla et al. 2014). As such, similarly to the red grouse, heavier black grouse males, i.e. those in better condition, are more likely to 
be able to cope with pressures on condition, such as parasite burden, whilst sustaining the physiological investment required to maintain growth and expression of a larger ornament (Höglund, Alatalo and Lundberg 1992, Mougeot, Evans and Redpath 2005b, Mougeot et al. 2009, Yang et al. 2013).

We also found that those males spending the most time on the lek and those achieving the most copulations expressed larger eye combs both before and during the breeding season. In many species, dominance status is accrued or maintained through extended time periods, not just during the breeding season (Andersson 1989, Höglund, Johansson and Pelabon 1997, McElligott et al. 1998, McGraw et al. 2001, Friedl and Klump 2005, Poisbleau et al. 2006). In black grouse, dominance-related interactions begin up to 3-5 months before breeding season, when males and female live in mixed-sex wintering flocks (Alatalo, Höglund and Lundberg 1991, Lebigre et al. 2012). Hence, ornament expression outside the breeding season has a function in social competition and future reproductive success. For example, in red grouse, the outcome of dominance-related interactions during the autumn heavily influences breeding success the following spring, and dominance is closely related to eye comb size in red grouse (Mougeot et al. 2003a, b).

Our results also show that between-year changes in dominance status are associated with larger eye combs. Males that attended the lek more frequently in the following year had larger eye combs near to the breeding season. A similar pattern but within-season has been observed in other species, such as the jungle fowl Gallus gallus in which changes in dominance led to changes in comb size (Cornwallis and Birkhead 2008). Similarly, changes in male dominance status in fallow deer (Dama dama) affects antler growth rate (Bartoš and Losos 1997, Ciuti and Apollonio 2011, also see Tibbetts and Safran 2009, Lantz and Karubian 2016). This indicates that those individuals able to increase their dominance can alter the expression of ornaments accordingly, and that having larger eye combs reflects dominance both before and during the breeding season (Rintamäki et al. 1999, Kokko et al. 1999).

\section{Younger males and dominance-related eye comb size}

Eye comb size was also related to dominance in younger males. The key difference between adults and younger males was that variation in eye comb size across younger males occurred later on and much closer to the breeding season. Younger males may be physiologically constrained from producing larger eye combs because they cannot produce high levels of 
testosterone, or may have fewer resources to allocate to ornament growth or maintenance. This may mean they should delay expressing larger ornaments until later in the season, in line with findings that younger males increase reproductive effort as adult male effort declines (Nieminen et al. 2016) or possibly not participate in dominance-related interactions until they have become an adult (Kokko 1997). Experimentally increased testosterone in younger males led to an increase in eye comb size (Siitari et al. 2007), but even then eye combs were not as large as adults, suggesting that physiological constraint may only be partly important. Since heavier younger males had large eye combs at all times, it seems that higher quality or better condition individuals are more likely to have the resources available to invest in ornament growth. As those younger males that participate in dominance behaviours are shown to invest in larger eye combs but later than adults, i.e. only as the breeding season approaches, it may also be that resource availability is a limiting factor (Lindström et al. 2009, Kervinen et al. 2012, see Dmitriew 2011 for a review). There is also evidence for this pattern in younger males of other avian species (e.g. house finches Haemorhous mexicanus, Badyaev and Duckworth 2003, bearded reedlings Panurus biarmicus, Surmacki, Stępniewski and Stępniewska 2015), suggesting that timing of investment in younger males is critical. Hence, whilst condition-dependent ornament expression is continuous across both age groups, there are differences in eye comb growth patterns towards the breeding season. These differences may be due to resource-based or physiological constraints in younger males, limiting their ability to grow large eye combs, which may also link to evidence of young males increasing reproductive effort with decline in adult male investment (Nieminen et al. 2016).

\section{Conclusions}

In summary, we found clear differences in eye comb size between ages and between dominant and subordinate males. In adults, dominant males had larger eye combs both before and during the breeding season. Males that increased their dominance between years increased their eye comb sizes. Younger males had smaller eye combs than adult males, and showed similar dominance-related patterns. The main difference between younger and adult males related to timing of eye comb size increase, with variation in younger male eye comb size occurring much later than in adults. We suggest this is due to physiological or resourcebased constraints. Our results suggest that, since dominance is accrued through year-round interactions in many species, the ability to maintain larger signals over prolonged periods and outside of the breeding season is likely to be beneficial, especially for adults. 


\section{Acknowledgements}

SH would like to thank the other authors and colleagues at the University of Lincoln for their dedicated time and effort in training and supporting this project. We would like to thank the Journal of Avian Biology editors and reviewers for their time and comments in reviewing this manuscript. We also thank Heli Siitari for her continued support of this research, and Rauno Alatalo (1952-2012) for his pioneering research into black grouse. We gratefully thank the Universities of Lincoln and Jyväskylä for their support and funding of the field work and scholarship required to produce this manuscript.

\section{References}

Alatalo, R. V., Höglund, J., Lundberg, A. and Rintamäki, P. T., Silverin, B. 1996. Testosterone and male mating success on the black grouse leks. - Proc R Soc Lond B 263: $1697-1702$.

Alatalo, R. V., Höglund, J., Lundberg, A. and Sutherland, W. J. 1992. Evolution of black grouse leks: female preferences benefit males in larger leks. - Behav. Ecol 3: 53-59.

Alatalo, R. V., Höglund, J. and Lundberg, A. 1991. Lekking in the black grouse- a test of male viability. - Nature 352: 155-156.

Alonso-Alvarez, C., Bertrand, S., Faivre, B., Chastel, O. and Sorci, G. 2007. Testosterone and oxidative stress: the oxidation handicap hypothesis. - Proc R Soc 274: 819-825.

Andersson, S. 1989. Sexual selection and cues for female choice in leks of Jackson's widowbird Euplectes jacksoni. - Behav Ecol Sociobiol 25: 403 - 410.

Andersson, M. 1994. Sexual Selection. - Princeton University Press, Princeton.

Badyaev, A. V. and Duckworth, R. A. 2003. Context-dependent sexual advertisement: plasticity in development of sexual ornamentation throughout the lifetime of a passerine bird. - J. Evol. Biol. 16: 1065-1076.

Balbontín, J., Hermosell, I. G., Marzal, A., Reviriego, M., de Lope, F. and Møller A. P. 2007. Age-related change in breeding performance in early life is associated with an increase in competence in the migratory barn swallow Hirundo rustica. - J. Anim. Ecol. 76: 915-925.

Barnard, P.. 1995. Timing of ornament growth, phenoptypic variation, and size dimorphism of two promiscuous African whydahs (polceidae: Vidua). - Biol. J. Linn. Soc. 55: 129 141. 
Bartoš, and Losos, S.. 1997. Response of antler growth to changing rank of fallow deer buck during the velvet period. - Can. J. Zool. 75: 1934-1939.

Bates, D. M., Maechler, M. and Bolker, B. 2015. Package 'lme4': linear mixed-effects models using S4 classes, R package, Version 0.999999- 2. - < http://cran.rproject.org/web/packages/lme4/lme4.pdf $\geq$ accessed 7 March 2018.

Bortolotti, G. R., Mougeot, F., Martinez-Padilla, J., Webster, L. M. and Piertney, S. B. 2009. Physiological stress mediates the honesty of social signals. - PLoS One 4: e4983.

Brittas, R. and Willebrand, T. 1991. Nesting habitats and egg predation in Swedish black grouse - Ornis Scandinavica. - Proc. 5th Internat. Symp. Grouse 22: 261 - 263.

Butler, M. W. and McGraw, K. J. 2011. Past or present? Relative contributions of developmental and adult conditions to adult immune function and coloration in mallard ducks (Anas platyhynchos). - J. Comp. Physiol. B. 181: 551 - 563.

Chaine, A. S. and Lyon, B. E. 2008. Intrasexual selection on multiple plumage ornaments in the lark bunting. - Anim. Behav. 76: 657-667.

Ciuti, S. and Apollonio, M. 2011. Do antlers honestly advertise the phenotypic quality of fallow buck (Dama dama) in a lekking population? - Ethol. 117: 133-144.

Cornwallis, C. K. and Birkhead, T. R. 2008. Plasticity in reproductive phenotypes reveals status-specific correlations between behavioral, morphological, and physiological sexual traits. -Evol. 62: 1149-1161.

Cotton, S., Fowler, K. and Pomiankowski, A. 2004. Condition dependance of sexual ornament size and variation in the stalk-eyed fly Cyrtodiopsis dalmanni (Diptera: Diopsidae). - Evol. 58: 1038-1046.

Dmitriew, C. M. 2011. The evolution of growth trajectories: what limits growth rate? - Biol. Rev. 86: $97-116$.

Dobson, F. S., Nolan, P. M., Nicolaus, M., Bajzak, C., Coquel, A. S. and Jouventin, P. 2008. Comparison of color and body condition between early and late breeding king penguins. - Ethol, 114: 925-933.

Doucet, S.M. and Mennill D.J. 2009. Dynamic sexual dichromatism in an explosively breeding Neotropical toad. - Biol. Lett.: p.rsbl20090604.

Dunn, P. O. and Cockburn, A. 1999. Extrapair mate choice and honest signalling in cooperatively breeding super fairy-wrens. - Evol. 53: 938 - 946.

Emlen, D. J., Warren, I.A., Johns, A., Dworkin, I. and Lavine, L.C. 2012. A mechanism of extreme growth and reliable signalling in sexually selected ornaments and weapons. Science 337: 860-864. 
Evans, S. R., Gustafsson, L. and Sheldon, B. C. 2011. Divergent patterns of age-dependence in ornamental and reproductive traits in the collared flycatcher. - Evol. 65: 1623 1636.

Faivre, B., Grégoire, A., Préault, M., Cézilly, F. and Sorci, G. 2003. Immune activation rapidly mirrored in a secondary sexual trait. - Science 300: 103-103.

Folstad, I. and Karter, A. J. 1992. Parasites, bright males, and the immunocompetence handicap.- Am Nat 139: 603-622.

Forstmeier, W. 2002. Benefits of early arrival at breeding grounds vary between males. - J. Anim. Ecol. 72: 1 - 9.

Friedl, T. W. P. and Klump, G. M. 2005. Sexual selection in the lek-breeding European treefrog: body size, chorus attendance, random mating and good genes. - Anim. Beh. 70: $1141-1154$.

Griggio, M., Serra, L., Licheri, D., Monti, A. and Pilatro, A. 2007. Armaments and ornaments in the rock sparrow: a possible dual utility of a carotenoid-based feather signal. Behav. Ecol. Sociobiol. 61: 423 - 433.

Hämäläinen, A., Alatalo, R. V., Lebigre, C., Siitari, H. and Soulsbury, C. D. 2012. Fighting behaviour as a correlate of male mating success in black grouse Tetrao tetrix. Behav. Ecol. Sociobiol. 66: 1577-1586.

Harms, N. J., Legagneux, P., Gilchrist, H. G., Bêty, J., Love, O. P., Forbes, M. R., Bortolotti, G. R. and Soos, C. 2015. Feather corticosterone reveals effect of moulting conditions in the autumn on subsequent reproductive output and survival in an Arctic migratory bird. - Proc. R. Soc. B. 282: 2014-2085.

Helminen, M. 1963. Composition of the Finnish populations of capercaillie, Tetrao urogallus, and black grouse, Lyrulus tetrix, in the autumns of 1952-1961, as revealed by a study of wings. - Riistatiet Julk 8:142-149.

Hill GE 1991. Plumage coloration is a sexually selected indicator of male quality. - Nature 350: 337-339.

Hill, G.E., Hood, W. R. and Huggins, K. 2009. A multifactorial test of the effects of carotenoid access, food intake and parasite load on the production of ornamental feathers and bill coloration in American goldfinches. - J. Expt. Biol. 212: 1225 1233.

Höglund, J., Alatalo, R. V. and Lundberg, A. 1992. The effects of parasites on male ornaments and female choice in the lekking black grouse (Tetrao tetrix). - Behav. Ecol. Sociobiol. 30: 71-76. 
Höglund, J., Johansson, T. and Pelabon, C. 1997. Behaviourally mediated sexual selection: characteristics of successful male black grouse. - Anim. Beh. 54: 255 - 264.

Holzer, B., Jacot, A. and Brinkhof, M. W. G. 2003. Condition-dependent signaling affects male sexual attractiveness in field crickets, Gryllus campestris. - Behav. Ecol. 14:353-359.

Horrocks, N., Perrins, C. and Charmantier, A. 2009. Seasonal changes in male and female bill knob size in the mute swan Cygnus olor. - J. Avian Biol. 40: 511-519.

Hovi, M., Alatalo, R. V., Höglund, J., Lundberg, A. and Rintamäki, P. T. 1994. Lek center attracts black grouse females. - Proc. R. Soc. B. 258: 303-305.

Hunt J., Brooks, R., Jennions, M. D., Smith, M. J., Bentsen, C. L., Bussière, L. F. 2004. High-quality male field crickets invest heavily in sexual display but die young. Nature 432: 1024 - 1027.

Jawor, J.M., Gray, N., Beall, S.M. and Breitwisch, R. 2004. Multiple ornaments correlate with aspects of condition and behaviour in female northern cardinals, Cardinalis cardinalis. - Anim. Beh. 67: 875-882.

Jenni, L. and Winkler, R. 2011. Moult and ageing of European passerines. A\&C Black

Kervinen, M., Alatalo, R. V., Lebigre, C., Siitari, H. and Soulsbury, C. D. 2012.

Determinants of yearling male lekking effort and mating success in black grouse (Tetrao tetrix). - Behav. Ecol. 23: 1209-1217.

Kervinen M, Lebigre C, Alatalo R. V., Siitari, H and, Soulsbury, C. D. 2015. Life-history differences in age-dependent expressions of multiple ornaments and behaviors in a lekking bird. - Am. Nat. 185: 13-27.

Kervinen, M., Lebigre, C. and Soulsbury, C. D. 2016. Simultaneous age-dependent and ageindependent sexual selection in the lekking black grouse (Lyrurus tetrix). - J. Anim. Ecol. 85: 712-725.

Kierdorf, U., Li, C. and Price, J. S. 2009. Improbable appendages: deer antler renewal as a unique case of mammalian regeneration. - Seminars Cell Develop. Biol. 20: 535-542.

Kitaysky, A. S., Wingfield, J. C. and Piatt, J. F. 1999. Dynamics of food availability, body condition and physiological stress response in breeding black-legged kittiwakes. Funct. Ecol. 13: 577-584.

Kokko, H. 1997. Evolutionarily stable strategies of age-dependent sexual advertisement. Behav. Ecol. Sociobiol. 41: 99 - 107.

Kokko, H. and Lindström, J. 1996. Kin selection and the evolution of leks: whose success do young males maximize? - Proc. R. Soc. B. 263: 919 - 923. 
Kokko, H., Lindström, J., Alatalo, R. V. and Rintamäki, P. T. 1998. Queuing for territory positions in the lekking black grouse (Tetrao tetrix). - Behav. Ecol. 9: 376-383.

Kokko, H., Rintamäki, P. T., Alatalo, R. V., Hoglund, J., Karvonen, E. and Lundberg, A. 1999. Female choice selects for lifetime lekking performance in black grouse males. Proc. R. Soc. B. 266: 2109-2116.

Kuznetsova, A., Brockhoff, P. B. and Christensen, R. H. 2015. Package: 'lmerTest': Tests in Linear Mixed Effects Models. R Package. Version: 2.0-25. < http://cran.rproject.org/web/packages/lmerTest/lmerTest.pdf > accessed 7 March 2018.

Langkilde, T. and Boronow, K. E. 2010. Color as a signal: The relationship between coloration and morphology in male eastern fence lizards, Sceloporus undulates. - J. Herpetol. 44: 261-271.

Lantz, S. M. and Karubian, J. 2016. Male Red-backed Fairywrens appear to enhance a plumage-based signal via adventitious molt. - Auk 133: 338-346.

Lebigre, C., Alatalo, R. V., Kilpimaa, J., Staszewski, V. and Siitari, H. 2012. Leucocyte counts variation and measures of male fitness in the lekking black grouse. $-\mathrm{J}$. Ornithol. 153: 95-102.

Lebigre, C., Alatalo, R. V. and Siitari, H. 2013. Physiological costs enforce the honesty of lek display in the black grouse (Tetrao tetrix). - Oecol. 172, 983-993.

Lee, W. S., Monaghan, P. and Metcalfe, N. B. 2012. The pattern of early growth trajectories affects adult breeding performance. - Ecol, 93: 902-912.

Lindström, J., Pike, T. W., Blount, J. D. and Metcalfe, N. B. 2009. Optimization of resource allocation can explain the temporal dynamics and honesty of sexual signals. - Am. Nat. 174: $515-525$.

Marra, P.P. and Holmes, R.T. 2001. Consequences of dominance-mediated habitat segregation in American redstarts during the nonbreeding season. - Auk 118: 92-104.

Martínez-Padilla, J., Pérez-Rodríguez, L., Mougeot, F., Ludwig, S. and Redpath, S. M. 2014. Intra-sexual competition alters the relationship between testosterone and ornament expression in a wild territorial bird. - Horm. Beh. 65: 435 - 444.

McElligott, A. G., Mattiangeli, V., Mattiello, S., Verga, M., Reynolds, C. A. and Hayden, T. J. 1998. Fighting tactics of fallow bucks (Dama dama, Cervidae): reducing the risks of serious conflict. - Ethol. 104: 789-803.

McGraw, K. J., Mackillop, E. A., Dale, J. and Hauber, M. E. 2002. Different colors reveal different information how nutritional stress affects the express of melanin- and structurally based ornamental plumage. - J. Exp. Biol. 205: 3747 - 3755. 
McGraw, K. J., Stoehr, A. M., Nolan, P. M. and Hill, G. E. 2001. Plumage redness predicts breeding onset and reproductive success in the house finch: a validation of Darwin's theory. - J. Avian. Biol. 32: 90-94.

Metcalfe, N. B. and Monaghan, P. 2001. Growth versus lifespan: perspectives from evolutionary ecology. - Expt. Geront. 38: 935 - 940.

Miller, L. K. and Brooks, R. 2005. The effects of genotype, age, and social environment on male ornamentation, mating behaviour and attractiveness. - Evol. 59: 2414-2425.

Møller, A. P. 1994. Phenotype-dependent arrival time and its consequences in a migratory bird. - Behav. Ecol. Sociobiol. 35: 115-122.

Mougeot, F., Dawson, A., Redpath, S.M., and Leckie, F. 2005a. Testosterone and autumn territorial behavior in male red grouse Lagopus lagopus scoticus. - Hormones. Behav. 47: 576-584.

Mougeot, F., Evans, S. A., and Redpath, S. M. 2005b.. Interactions between population processes in a cyclic species: parasites reduce autumn territorial behaviour of male red grouse. - Oecol. 144: 289-298.

Mougeot, F., Martinez-Padilla, J., Webster, L. M. I., Blount, J. D., Pérez-Rodríguez, L. and Piertney S. B. 2009. Honest sexual signalling mediated by parasite and testosterone effects on oxidative balance. - Proc. R. Soc. B. 276: 1093-1100.

Mougeot, F., Piertney, S. B., Leckie, F., Evans, S., Moss, R., Redpath, S. M. and Hudson, P. J. 2005c. Experimentally increased aggressiveness reduces population kin structure and subsequent recruitment in red grouse Lagopus lagopus scoticus. - J. Anim. Ecol. 74: 488-497.

Mougeot, F., Redpath, S. M., Leckie, F., and Hudson, P.J. 2003a.. The effect of aggressiveness on the population dynamics of a territorial bird. - Nature 421: 737 739.

Mougeot, F., Redpath S. M., Moss, R., Matthiopoulos J, and Hudson, P. J. 2003b.. Territorial behaviour and population dynamics in red grouse Lagopus lagopus scoticus. I. Population experiments. - J. Anim. Ecol. 72: 1073-1082.

Mougeot, F., Redpath, S. M., Piertney, S. B. 2006. Elevated spring testosterone increases parasite intensity in male red grouse. - Behav. Ecol. 17: 117 - 125.

Murphy, T. G., Rosenthal, M.F., Montgomerie, R.,, Tarvin. K. A. 2009. Female American goldfinches use carotenoid-based bill coloration to signal status. - Behav. Ecol. 20: 1348-1355. 
Nieminen, E., Kervinen, M., Lebigre, C. and Soulsbury, C.D. 2016. Flexible timing of reproductive effort as an alternative mating tactic in black grouse (Lyrurus tetrix) males. Behav. 153: 927-946.

Ninni, P., de Lope, F., Saino, N., Haussy, C. and Møller, P.M. 2004. Antioxidants and condition-dependence of arrival date in a migratory passerine. - Oikos 105: 55 - 64 .

Nussey, D. H., Kruuk, L. E., Morris, A., Clements, M. N., Pemberton, J. M. and CluttonBrock, T. H. 2009. Inter-and intrasexual variation in aging patterns across reproductive traits in a wild red deer population. - Am. Nat. 174: 342-357.

Oliveira, R. F. 2004. Social modulation of androgens in vertebrates: mechanisms and function. - Adv. Stu. Beh. 34: 165 - 239.

Pérez-Rodríguez, L. 2008. Carotenoid-based ornamentation as a dynamic but consistent individual trait. - Behav. Ecol. Sociobiol. 62: 995-1005.

Peters, A., Astheimer, L. B. and Cockburn, A. 2001. The annual testosterone profile in cooperatively breeding superb fairy-wrens, Malurus cyaneus, reflects their extreme infidelity. - Behav. Ecol. Sociobiol. 50: 519-527.

Pike, T. W., Blount, J. D., Lindström, J. and Metcalfe, N. B. 2010. Dietary carotenoid availability, sexual signalling and functional fertility in sticklebacks. - Biol. Lett. 6 : 191-193.

Poisbleau, M., Fritz, H., Valeix, M., Perroi, P., Dalloyau, S. and Lambrechts, M. M. 2006. Social dominance correlates and family status in wintering dark-bellied brent geese, Branta bernicla bernicla. - Anim. Behav. 71: 1351-1358.

Prum, R. O. and Torres, R. 2003. Structural colouration of avian skin: convergent evolution of coherently scattering dermal collagen arrays. - J. Exp. Biol. 206: 2409-2429.

Pryke, S. R., Andersson, S., Lawes, M. J. and Piper, S. E. 2002. Carotenoid status signalling in captive and wild red-collared widowbirds: independent effects of badge size and color. - Behav. Ecol. 13: 622 - 631 .

R Development Core Team. 2012. R: a language and environment for statistical computing. R Foundation for Statistical Computing, Vienna, Austria: R Foundation for Statistical Computing. < http://www.r-project.org > accessed 7 March 2018.

Rands, S.A., Evans, M.R. and Johnstone, R.A. 2011. The dynamics of honesty: modelling the growth of costly, sexually-selected ornaments. - PLoS One 6: 1-7.

Rasband, W.S. 2012. ImageJ. Version 1.46r. US National Institutes of Health, Bethesda, MD. < http://imagej.nih.gov/ij/ > Accessed 7 March 2018. 
Reudink, M.W., Marra, P.P., Kyser, K., Boag, P.T., Langin, K.M. and Ratcliffe, L.M. 2009. Non-breeding season events influence sexual selection in a long-distance migratory bird. - Proc. R. Soc. Lond. B. 276: 1619 - 162.

Rintamäki, P., Alatalo, R. V., Höglund, J. and Lundberg, A. 1997. Fluctuating asymmetry and copulation success in lekking black grouse. - Anim. Beh. 54: 265-269.

Rintamäki, P., Höglund, J., Karvonen, E., Alatalo, R. V., Björklund, N., Lundberg, A., Rätti, O. and Vouti, J. 2000. Combs and sexual selection in black grouse (Tetrao tetrix). Behav. Ecol. 11: 465-471.

Rintamäki, P. T., Karvonen, E., Alatalo, R.V. and Lundberg, A. 1999. Why do black grouse perform on lek sites outside the breeding season? - J. Avian Biol. 30: 359-366.

Rintamäki, P. T., Höglund, J., Alatalo, R. V., Lundberg, A. 2001. Correlates of male mating success on black grouse (Tetrao tetrix L.) leks. - Ann. Zoo. Fenn. 38: 99-109.

Rosenthal, M. F., Murphy, T. G., Darling, N. and Tarvin, K. A. 2012. Ornamental bill color rapidly signals changing condition. - J. Avian Biol. 43: 553 - 564.

Saino, N., Romano, M., Caprioli, M., Lardelli, R., Micheloni, P., Scandolara, C., Rubolini, D. and Fasola, M. 2013. Molt, feather growth rate and body condition of male and female barn swallows. - J. Ornith. 154: 537-547.

Serra, L., Griggio, M., Licheri, D. and Pilastro, A. 2007. Moult speed constrains the expression of a carotenoid-based sexual ornament. - J. Evol. Biol. 20: 2028-2034.

Setchell, J.M. and Dixson, A.F. 2001. Changes in the secondary sexual adornments of male mandrills (Mandrillus sphinx) are associated with gain and loss of alpha status. Horm. Beh. 39: 177 - 184.

Siefferman, L., Hill, G. E. and Dobson, F. S. 2005. Ornamental plumage coloration and condition are dependent on age in eastern bluebirds Sialis sialis. - J. Avian. Biol. 36: 428-435.

Siitari, H., Alatalo, R. V., Halme, P., Buchanan, K. L. and Kilpimaa, J. 2007. Color signals in the black grouse (Tetrao tetrix): signal properties and their condition dependency. Am. Nat. 169: 81-92.

Stearns, S. C. 1989. Trade-offs in life-history evolution. - Funct. Ecol. 3: 259- 268.

Surmacki, A., Stępniewski, J. and Stępniewska M. 2015. Juvenile sexual dimorphism, dichromatism and condition-dependent signalling in a bird species with early pair bonds. - J. Ornith. 156: 65-73.

Tibbetts, E. A. and Safran, R. J. 2009. Co-evolution of plumage characteristics and winter sociality in New and Old World sparrows. - J. Evol. Biol. 22: 2376-2386. 
Torres, R. and Velando, A. 2003. A dynamic trait affects continuous pair assessment in the blue-footed booby, Sula nebouxii. - Behav. Ecol. Sociobiol. 55: 65 - 72.

Vannoni, E. and McElligott, A. G. 2009. Fallow bucks get hoarse: vocal fatigue as a possible signal to conspecifics. - Anim. Behav. 78: 3-10.

Velando, A., Beamonte-Barrientos R, Torres R 2006. Pigment-based skin colour in the bluefooted booby: an honest signal of current condition used by females to adjust reproductive investment. - Oecol. 149: 535-542.

von Schantz, T., Bensch, S., Grahn, M., Hasselquist, D. and Wittzell, H. 1999. Good genes, oxidative stress and condition-dependent sexual signal. - Proc. R. Soc. Lond. B. 266: $1-12$.

Walther, B.A., and Clayton, D.H. 2005. Elaborate ornaments are costly to maintain: evidence for high maintenance handicaps. - Behav. Ecol. 16: 89-95.

Willebrand, T. and Marcström, V. 1989. Marrow, heart and body fat as indicators of black grouse Tetrao tetrix condition - Ornis Scandinavica. 20: 49-52.

Wolak, M.E., Fairbairn D.J. and Paulsen, Y.R. 2012. Guidelines for estimating repeatability. Methods - Ecol. Evol. 3: 129-137.

Yang, C., Wang, J., Fang, Y. and Sun, Y.H. 2013. Is sexual ornamentation an honest signal of male quality in the Chinese grouse (Tetrastes sewerzowi)? - PLoS ONE 8: e82972.

Yoccoz, N.G., Mysterud, A., Langvatn, R. and Stenseth, N.C. 2002. Age- and densitydependent reproductive effort in male red deer. Proc. R. Soc. B. 269:1523 - 1528.

Yoshino, K., Goshima, S. 2002. Sexual dominance in hermit crab shell fights: asymmetries in owner-intruder status, crab size, and resource value between sexes. - J. Ethol. 20: 63 -69 .

Zahavi, A. 1975. Mate selection - a selection for a handicap. - J. Theor. Biol. 53: 205-214. 


\section{Figure Legends}

Figure 1: Supra-orbital red eye combs of black grouse. Photographs show an adult male caught in the (a) before the breeding season (30th January) and again (b) during the breeding season (16th May). (c) Supraorbital eye comb size for adult males (dashed line, open circles) and younger (solid line, solid points) male black grouse before and during the breeding season. Individual data points are shown.

a)

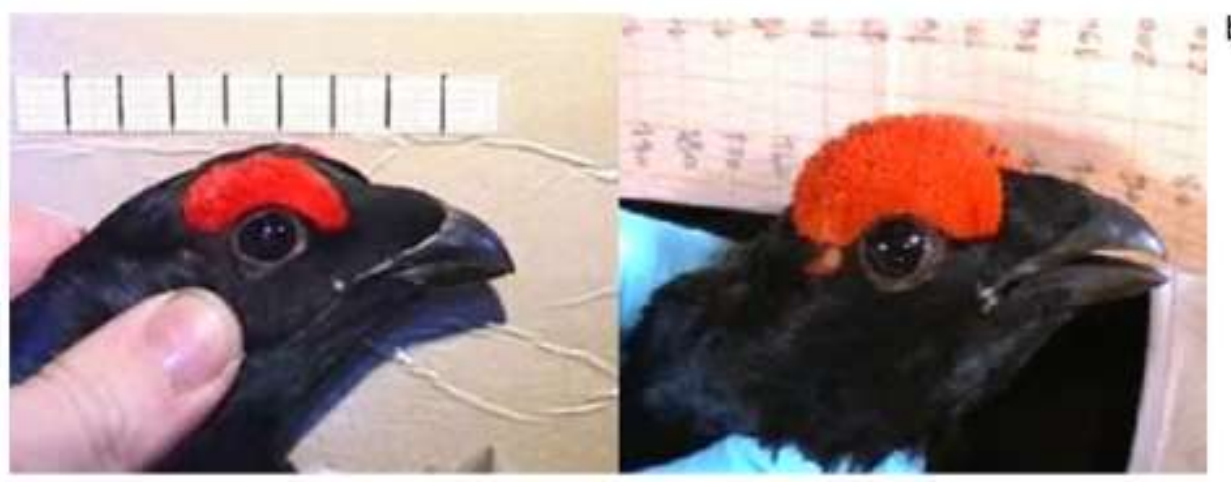

(c)

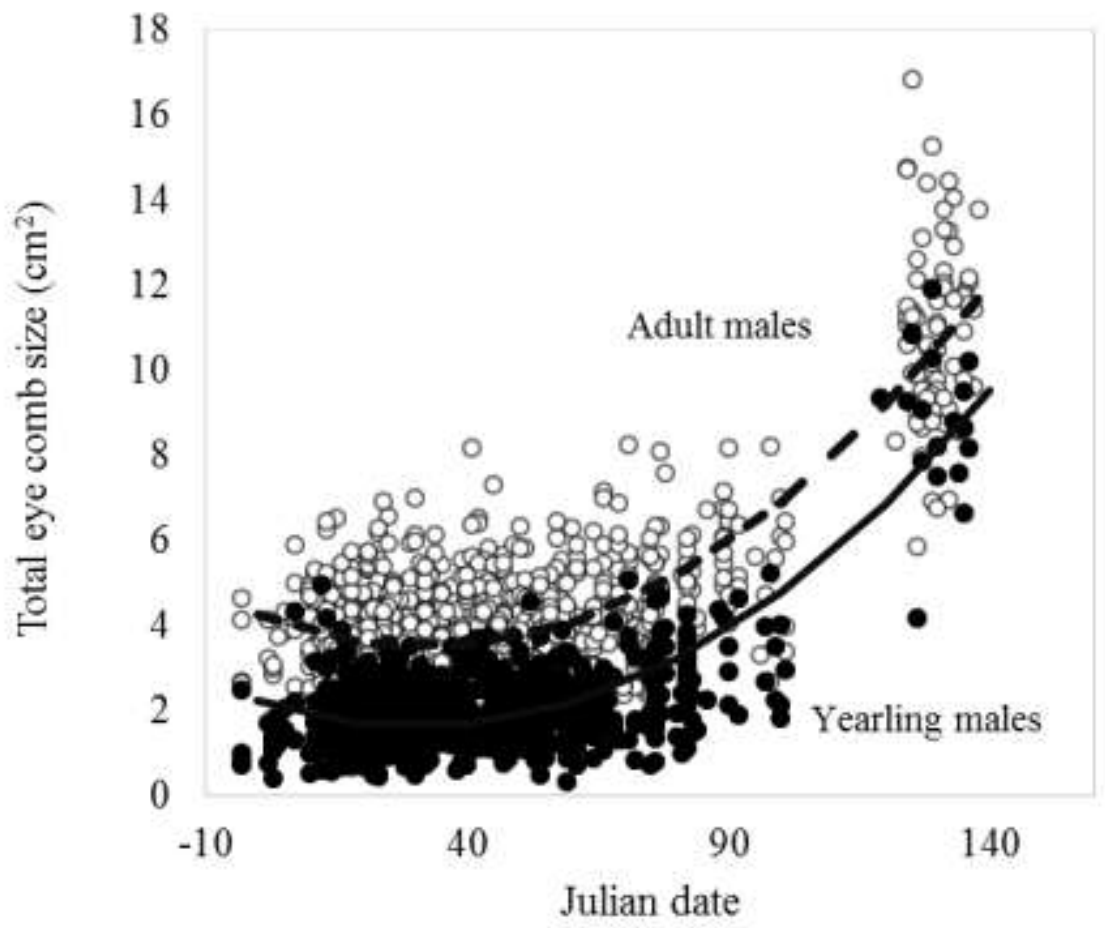


Figure 2: The relationship between adult eye comb growth, Julian date and (a) log body mass (dashed line $=$ heavy $(1400 \mathrm{~g})$ male, solid line = light $(1100 \mathrm{~g})$ male), (b) lek attendance (dashed line $=$ high attender, solid line $=$ low attender) and (c) mating success (dashed line $=$ males mating with high success ( $>5$ copulations), solid line $=$ males unsuccessful $(0$ copulations) in mating). Individual data points are shown and illustrative fitted lines represent dominant and subordinate individuals.
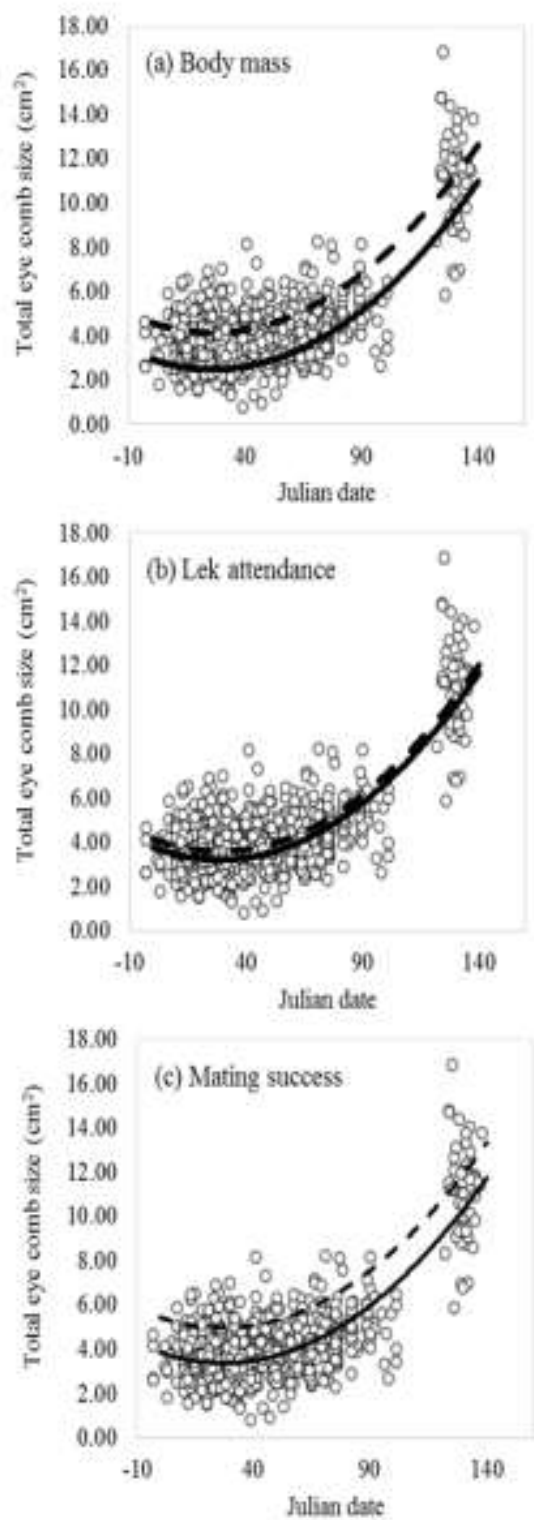
Figure 3: The relationship between younger male eye comb growth, Julian date and (a) log body mass (dashed line $=$ heavy $(1400 \mathrm{~g})$ male, solid line $=$ light $(1100 \mathrm{~g})$ male), (b) lek attendance $($ dashed line $=$ high attender, solid line $=$ low attender), $(\mathrm{c})$ distance from lek centre $($ dashed line $=$ male close to lek centre $(\leq 20 \mathrm{~m})$, solid line $=$ male far from lek centre $(\geq 80 \mathrm{~m}))$ and $(\mathrm{d})$ mating success $($ dashed line $=$ successful male $(5$ copulations $)$, solid line $=$ males unsuccessful ( 0 copulations) in mating). Individual data points are shown and illustrative fitted lines represent dominant and subordinate individuals.
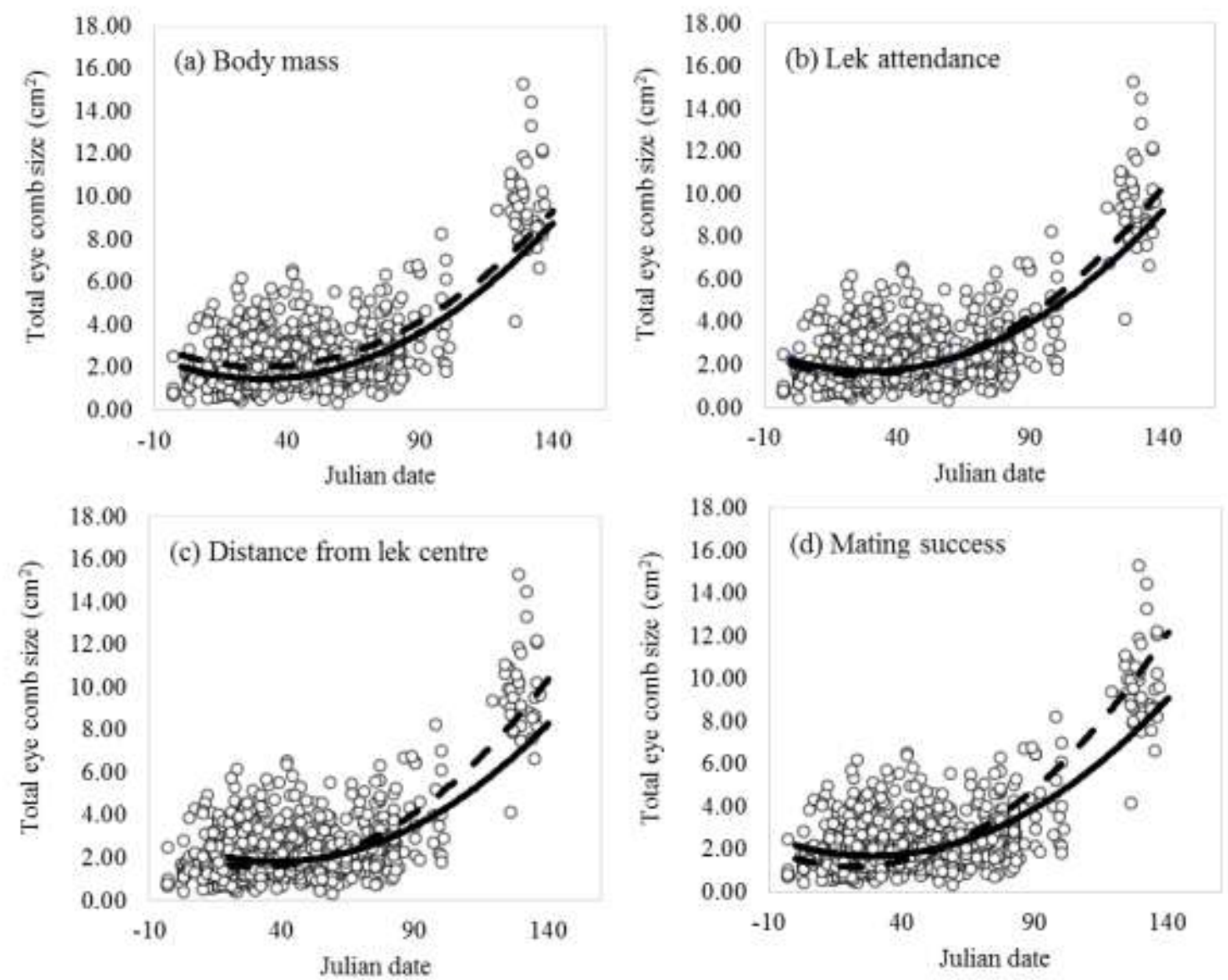

'This article is protected by copyright. All rights reserved.' 
Figure 4: Adult male eye comb area in relation to Julian date and between-year changes in lek attendance.

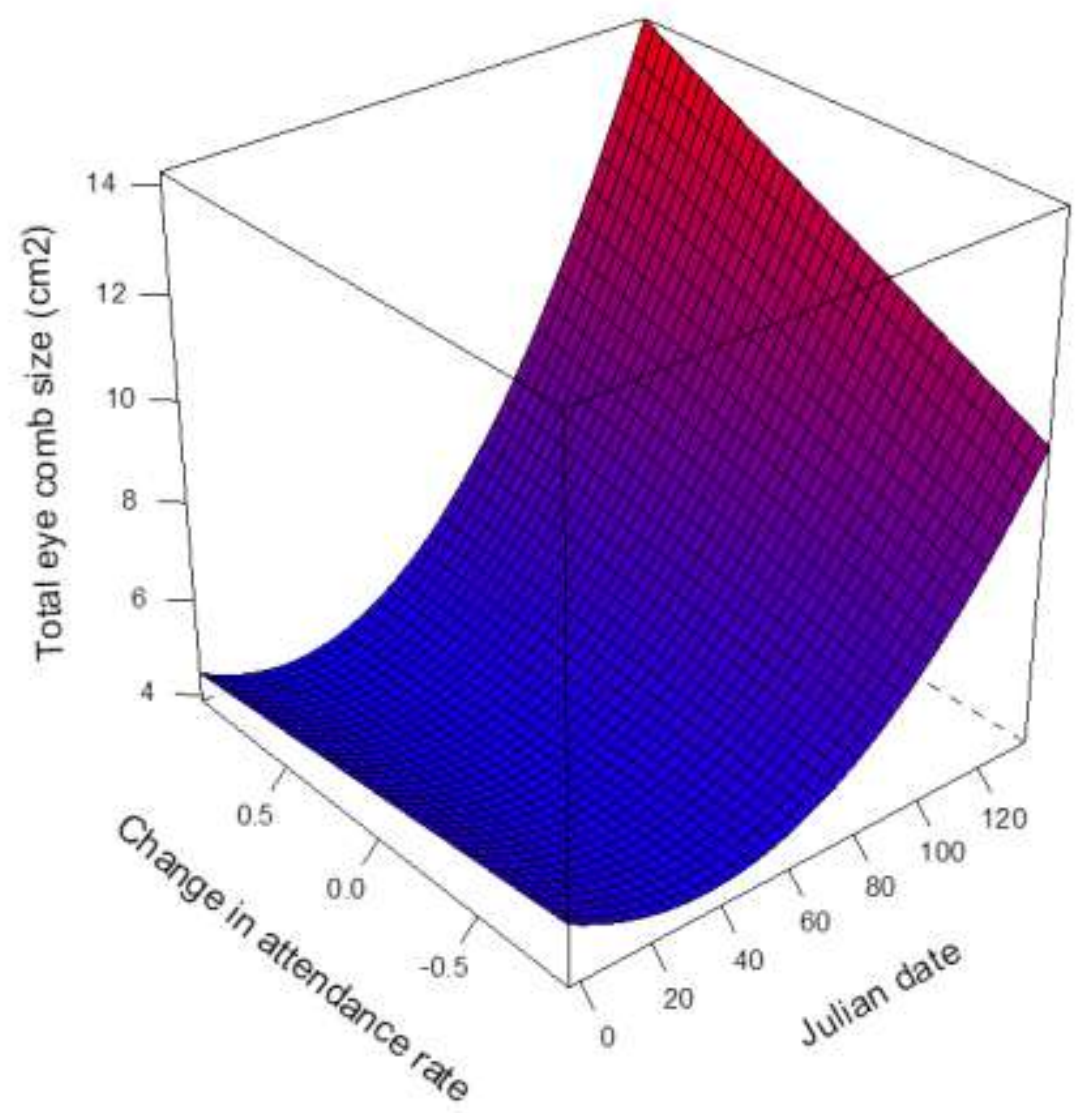

'This article is protected by copyright. All rights reserved.' 


\section{Table Legends}

Table 1: Outputs for LMM models testing the variation in relationship between eye comb area (dependent variable) and Julian date according to 4 condition and dominance-related morphological and behavioural traits.

\begin{tabular}{|c|c|c|c|c|c|c|c|c|c|}
\hline & & \multicolumn{4}{|c|}{ Younger males } & \multicolumn{4}{|c|}{ Adult males } \\
\hline Model & Variable & $\begin{array}{r}\text { Estim } \\
\text { ate }\end{array}$ & $\pm \mathrm{SE}$ & $t$ & $P$ & $\begin{array}{r}\text { Estim } \\
\text { ate }\end{array}$ & $\pm \mathrm{SE}$ & $t$ & $p$ \\
\hline $\begin{array}{c}\text { Body mass } \\
\text { Younger } \\
\text { males }\end{array}$ & Intercept & -12.65 & 4.03 & $\begin{array}{r}3.1 \\
4\end{array}$ & $\begin{array}{r}<0.0 \\
01\end{array}$ & -46.25 & 6.53 & $\begin{array}{r}7.0 \\
7\end{array}$ & $\begin{array}{r}<0.0 \\
01\end{array}$ \\
\hline $\begin{array}{l}(751 \\
\text { males/7 } \\
59\end{array}$ & $\begin{array}{l}\text { Julian date } \\
\text { (linear) }\end{array}$ & -0.04 & 0.01 & $\begin{array}{r}- \\
11 . \\
33\end{array}$ & $\begin{array}{r}<0.0 \\
01\end{array}$ & -0.04 & 0.01 & $\begin{array}{r}- \\
7.6 \\
5\end{array}$ & $\begin{array}{r}<0.0 \\
01\end{array}$ \\
\hline $\begin{array}{l}\text { observat } \\
\text { ions) }\end{array}$ & $\begin{array}{l}\text { Julian date } \\
\text { (quadratic) }\end{array}$ & $\begin{array}{r}6.11 x \\
10^{-4}\end{array}$ & $\begin{array}{r}2.82 \mathrm{x} \\
10^{-5}\end{array}$ & $\begin{array}{r}21 . \\
68\end{array}$ & $\begin{array}{r}<0.0 \\
01\end{array}$ & $\begin{array}{r}6.56 \mathrm{x} \\
10^{-4}\end{array}$ & $\begin{array}{r}3.40 \mathrm{x} \\
10^{-5}\end{array}$ & $\begin{array}{r}19 . \\
29\end{array}$ & $\begin{array}{r}<0.0 \\
01\end{array}$ \\
\hline $\begin{array}{l}\text { Adults } \\
(542 \\
\text { males/ } \\
796 \\
\text { observat } \\
\text { ions) }\end{array}$ & Body mass & 2.12 & 0.57 & $\begin{array}{r}3.7 \\
2\end{array}$ & $\begin{array}{r}<0.0 \\
01\end{array}$ & 7.02 & 0.92 & $\begin{array}{r}7.6 \\
6\end{array}$ & $\begin{array}{r}<0.0 \\
01\end{array}$ \\
\hline $\begin{array}{l}\text { Lek } \\
\text { attendance }\end{array}$ & Intercept & 2.22 & 0.24 & $\begin{array}{r}9.9 \\
3\end{array}$ & $\begin{array}{r}<0.0 \\
01\end{array}$ & 3.79 & 0.25 & $\begin{array}{r}15 . \\
09\end{array}$ & $\begin{array}{r}<0.0 \\
01\end{array}$ \\
\hline $\begin{array}{l}\text { Younger } \\
\text { males } \\
(209\end{array}$ & $\begin{array}{l}\text { Julian date } \\
\text { (linear) }\end{array}$ & -0.04 & 0.01 & $\begin{array}{r}- \\
6.0 \\
7\end{array}$ & $\begin{array}{r}<0.0 \\
01\end{array}$ & -0.04 & 0.01 & $\begin{array}{r}6.5 \\
8\end{array}$ & $\begin{array}{r}<0.0 \\
01\end{array}$ \\
\hline males $/ 2$ & Julian date & $6.16 x$ & $4.57 x$ & 13. & $<0.0$ & $6.82 x$ & $4.19 x$ & 16. & $<0.0$ \\
\hline 25 & (quadratic) & $10^{-4}$ & $10^{-5}$ & 46 & 01 & $10^{-4}$ & $10^{-5}$ & 30 & 01 \\
\hline $\begin{array}{l}\text { observat } \\
\text { ions) } \\
\text { Adults }\end{array}$ & Lek attendance & -0.21 & 0.18 & $\begin{array}{r}- \\
1.3 \\
8\end{array}$ & $\begin{array}{r}0.23 \\
0\end{array}$ & 0.38 & 0.11 & $\begin{array}{r}3.3 \\
5\end{array}$ & $\begin{array}{r}<0.0 \\
01\end{array}$ \\
\hline$(302$ & Julian date & - & - & - & - & - & - & - & - \\
\hline
\end{tabular}




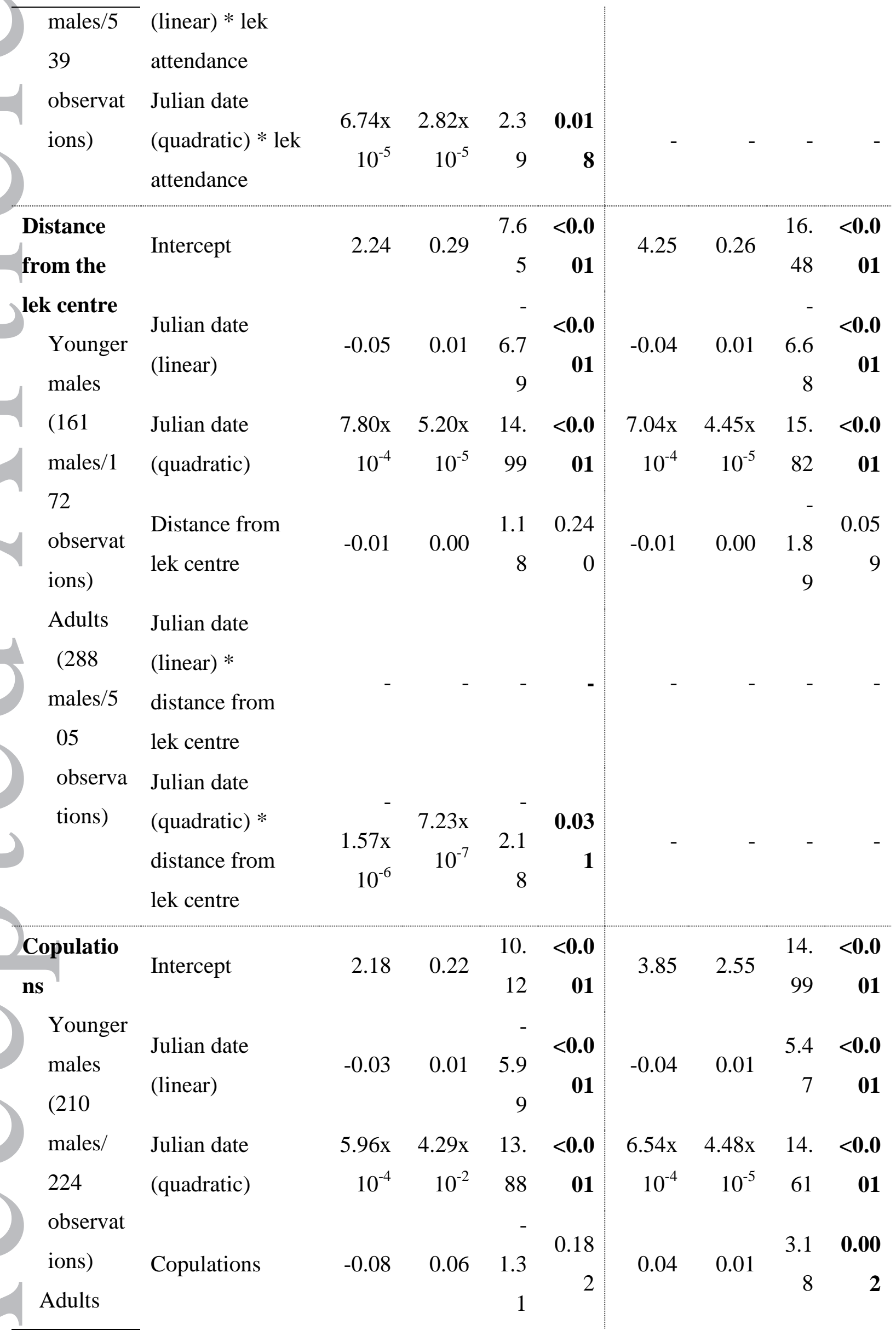


(290 Julian date

males/49 (linear)*copulati

3 observati Julian date

ons) (quadratic)*copu

lations
$2.36 \mathrm{x} \quad 5.95 \mathrm{x}$

$10^{-5} \quad 10^{-6}$

$\begin{array}{rr} & \\ - & - \\ 3.9 & <\mathbf{0 . 0} \\ 7 & \mathbf{0 1}\end{array}$

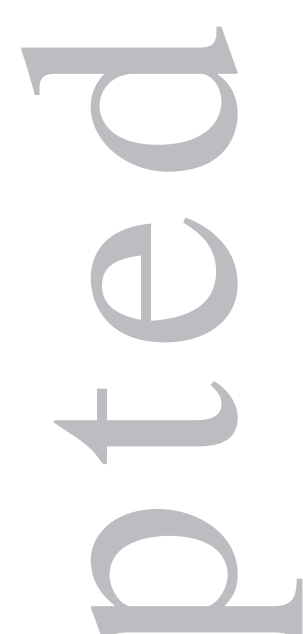


Table 2: LMM model outputs for the relationship between eye comb size and Julian date and changes in dominance-related traits in male black grouse.

\begin{tabular}{llrrrr}
\hline Model & Variable & Estimate & SE & $\boldsymbol{T}$ & $\boldsymbol{p}$ \\
\hline Change in distance & Intercept & 4.45 & 0.36 & 12.36 & $<\mathbf{0 . 0 0 1}$ \\
from lek centre & Julian date (linear) & -0.03 & 0.12 & -2.62 & $\mathbf{0 . 0 1 0}$ \\
(91 individuals/152 & Julian date (quadratic) & $6.44 \times 10^{-}$ & 8.54 & & \\
data points) & & 4 & $\times 10^{-5}$ & 7.53 & $<\mathbf{0 . 0 0 1}$ \\
& Distance from lek centre & $3.41 \times 10^{-}$ & 5.27 & \\
& & 3 & $\times 10^{-4}$ & 0.65 & 0.519 \\
Change in lek & Intercept & 4.07 & 0.33 & 14.14 & $<\mathbf{0 . 0 0 1}$ \\
attendance & Julian date (linear) & -0.04 & 0.01 & -3.74 & $<\mathbf{0 . 0 0 1}$ \\
(93 individuals/167 & Julian date (quadratic) & $6.95 \times 10^{-}$ & 7.74 & 8.98 & $<\mathbf{0 . 0 0 1}$ \\
data points) & Lek attendance & -0.04 & 0.04 & -1.08 & 0.283 \\
& Julian date & & & & \\
& (quadratic)*Lek & $1.70 \times 10^{-}$ & $6.02 \times 10^{-}$ & & \\
& attendance & 4 & 5 & 2.82 & $\mathbf{0 . 0 0 6}$ \\
& & & & & \\
\hline
\end{tabular}

